\title{
Pengaruh Tingkat Kecemasan dan Mekanisme Koping Ibu Primigravida terhadap Lamanya Kala I Persalinan Spontan
}

\author{
Sri Yunita Perangin Angin \\ Universitas Audi Indonesia \\ ${ }^{*}$ corresponding author \\ Sri Yunita Persangin Angin \\ sriyunita237@gmail.com
}

\begin{abstract}
Abstrak
Lama persalinan abnormal pada wanita nulipara (kehamilan pertama) dapat dipengaruhi oleh kecemasan berat selama persalinan. Kecemasan tersebut terkait dengan mekanisme penangkaran maladaptif. Tujuan penelitian ini adalah untuk menganalisis pengaruh tingkat kecemasan dan mekanisme koping wanita nulipara terhadap lama persalinan kala I. Jenis penelitian ini adalah survei analitik dengan tipe penelitian eksplanatori. Sampel berjumlah 40 wanita dengan menggunakan teknik total sampling. Pengumpulan data dilakukan dengan menggunakan lembar observasi dan wawancara serta dianalisis dengan metode regresi logistik ganda. Hasil penelitian menunjukkan bahwa tingkat kecemasan $(p=0,001)$ dan mekanisme koping $(p=0,001)$ berpengaruh nyata terhadap lama persalinan kala $I$, di mana ibu yang mengalami kecemasan berat 13 kali berisiko mengalami lama persalinan kala I yang abnormal $(\mathrm{OP}=13,49 ; 95 \% \mathrm{Cl} .1 .94 ; 93.81)$ dibandingkan dengan ibu yang mengalami kecemasan sedang, sedangkan mekanisme koping maladaptif memiliki risiko 10 kali lipat mengalami lama persalinan kala I yang abnormal $(O R=10,23 ; 95 \% \mathrm{Cl} 1.67$; 62.60) dibandingkan dengan mekanisme caping adaptif. Disarankan agar suami mendukung istrinya untuk mengurangi kecemasan ibu selama proses persalinan.
\end{abstract}

Kata kunci: Lama Persalinan Kala I; Tingkat Kecemasan; Mekanisme Koping

\section{The Effect of Anxiety Levels and Coping Mechanism of The Primigravida Against the Length of First Stage of Spontant Labor}

\begin{abstract}
Abnormal length of first stage of labor in nulliparous woman (first pregnant) can be influenced by severe anxiety during labor. The anxiety is related to maladaptive coping mechanism. The purpose of this study was to analyze the effect of anxiety level and coping mechanism of nulliparous woman on the length of first stage of labor. This research was analytical survey with explanatory research type. The samples consisted of 40 woman using total sampling technique. The date was gathered by using observation and interview sheets and analyzed using multiple logistic regression methods. The results showed that the level of anxiety $(p=0,001)$ and coping mechanism $(p=0,001)$ had a significant effect on the length of the first stage of labor, in which mother who had severe anxiety would have 13 time risk having abnormal length of first stage of labor $(O P=13,49 ; 95 \% C l .1 .94 ; 93.81)$ compared with
\end{abstract}


mother who had moderate anxiety, while maladaptive coping mechanisms would have 10 times risk having abnormal length of first stage of labor (OR=10,23;95\% Cl 1.67;62.60) compared with the adaptive coping mechanism. It is recommended that the husband should support their wives to reduce maternal anxiety during the labor process.

Keyword: Length of First Stage of Labor; Level of Anxiety; Coping Mechanism

\section{Pendahuluan}

Angka kematian dan angka kesakitan ibu hamil maupun bersalin merupakan persoalan untuk negara berkembang. Sekitar $20-40 \%$ wanita usia subur mengalami kematian di negara miskin yang berkaitan dengan kehamilan. WHO mengeluarkan data AKI di dunia selama kehamilan dan persalinan menyentuh angka 515.000 jiwa disetiap tahunnya (WHO,2008).

Upaya untuk mengurangi tingginya angka kematian ibu dapat dilakukan seperti serta menyediakan pelayanan kesehatan untuk ibu bersalin yang berkualitas baik. Hal tersebut dapat dilakukan dengan memberikan pertolongan persalinan secara tepat sehingga persalinan kala I lama dapat dihindari. Dengan demikian resiko persalinan seperti seksio sesaria, persalinan dengan vakum ekstrasi yang berisiko untuk ibu atau bayi dapat dikurangi.

Tingkat angka kematian ibu (AKI) di ASEAN, negara Indonesia merupakan negara dengan nilai AKI tinggi, pada tahun 2006 tercatat 225/100.000 KH, dan tahun 2007 tercatat 248/100.000 KH. Sedangkan jika melihat target Indonesia pada Millenium Development Goals (MDG) tahun 200, diharapkan AKI dapat mencapai angka 125/100.000 KH. Angka kematia ibu yang termasuk tinggi ini dikarenakan beberapa hal seperti ekonomi, pendidikan, sosial, budaya, kesehatan dan gender (SDKI, 2007).

Provinsi Sumatera Utara menunjukkan adanya kecenderungan penurunan angka kematian ibu (AKI), dari 330/100.000 $\mathrm{KH}$ tahun 2004, $320 / 100.000 \mathrm{KH}$ tahun 2005, $315 / 100.000 \mathrm{KH}$ tahun 2006, 275/100.000 KH pada tahun 2007 (Dinkes Provsu, 2008).

Kematian ibu yang terjadi waktu bersalin sebanyak 50,09\%, kematian ibu waktu nifas sebanyak $30,58 \%$, dan saat kehamilan sebanyak 19,33\%. Di Indonesia, beberapa pemicu langsung terjadinya kematian pada ibu adalah perdarahan 
Pengaruh Tingkat Kecemasan dan Mekanisme Koping Ibu Primigravida terhadap Lamanya Kala I Persalinan Spontan

sebanyak $45,2 \%$, eklampsi sebanyak 12,9\%, komplikasi pada aborsi sebanyak $11,1 \%$, sepsis postpartum $9,6 \%$, anemia $1,6 \%$ dan pemicu tidak langsung kematian ibu sebanyak $14,1 \%$ (WHO,2008).

Tingkat kecemasan tinggi pada ibu primigravida selama waktu proses bersalin terutama kala I menjadi persoalan yang tidak jarang dihadapi. Hal ini dapat dikarenakan oleh faktor psikis yang dapat berupa kurangnya kepedulian dari penolong persalinan sehingga menyebabkan terjadinya kejadian persalinan lama, fetal distress, kematian pada maternal.

Ibu yang bersalin dengan rasa percaya diri, dan nyaman atau rileks akan menimbulkan mekanisme koping yang dapat membantu menurunkan rasa nyeri selama persalinan dan proses persalinan dapat berjalan dengan normal (Read, 1994). Dukungan suami/ keluarga dan perasaan ibu yang pasrah mananti kelahiran bayinya dapat menyebabkan terbentuknya kondisi koping yang adaptif (Fraser et all, 2009).

Primus (1990) melakuan penelitian terhadap hubungan faktor psikis terhadap lama persalinan yang didapatkan kecemasan yang meningkat pada ibu serta bayi dengan rasio kasus persalinan yang lama sebesar $28,2 \%$, namun tidak terdapat laporan kematian perinatal.

Diponogoro

mendapatkan kecemasan rendah yang dirasakan ibu bersalin memiliki kaitan dengan proses bersalin yang lebih cepat terhadap primigravida.

$$
\text { Handayani }
$$
mendapatkan perbedaan pada tingkat kecemasan yang dialami ibu primigravida dan multipara selama proses bersalin. Hasilnya pada ibu primigravida memiliki kecemasan lebih tinggi dari ibu multipara dalam menghadapi proses persalinan. Hasil ini selaras dengan penelitian Utami (2009), dan Ambarwati (2001) di mana didapatkan ibu hamil dengan persalinan anak yang pertama, rasa cemas yang dihadapi lebih tinggi jika dibandingkan mereka yang telah melahirkan sebelumnya.

Kondisi kurang efisiennya kontraksi pada uterus akibat tingkat kecemasan yang tinggi pada ibu primigravida merupakan penyebab terjadinya persalinan lama $56 \%$ menurut penelitian yang telah ada. Od el all (2000) menyebutkan bahwa terdapat difungsional pada kontraksi uterus yang merupakan respon dari 
tingkat kecemasan yang tinggi waktu persalinan berlangsung sehingga aktivitas uterus terhambat dan menyebabkan penipisan pada mulut rahim melambat dan semakin lama proses dilatasi. Kondisi tersebut merupakan bagian dari psikologis, sehingga psikologis memiliki dampak pada lama waktu bersalin.

Hasil studi pendahuluan yang telah dilakukan selama Juli sampai dengan September 2012 di Klinik Bersalin Kasih Ibu wilayah kerja dari Puskesmas Delitua Kabupaten Deli Serdang didapatkan jumlah persalinan pada primigravida 84 orang dengan lama kala I: 10-14 jam dengan kondisi normal (42,55\%), >24 jam $(19,15 \%)$ dirujuk ke rumah sakit. Sedangkan persalinan multipara sebanyak 112 orang dengan lama kala I: 4-8 jam dengan kondisi normal (79,46\%), > 8- 12 jam (12,25\%), 12-16 jam (5,36\%), >16 jam (2,68\%) dirujuk ke rumah sakit.

Tingkat kecemasan yang tinggi yang dirasakan oleh ibu primigravida yang bersalin membuat pentingnya peran penolong persalinan untuk menurunkan rasa cemas tersebut sehingga ibu bersalin dapat mempersiapkan diri menghadapi persalinan dengan rasa tenang dan dapat membantu terbentuknya koping yang adaptif.

Tujuan dari penelitian adalah untuk menganalisis pengaruh dari tingkat kecemasan dan mekanisme koping pada ibu primigravida terhadap lamanya kala I bersalin spontan di klinik bersalin swasta wilayah kerja Puskesmas Delitua Kabupaten Deli Serdang.

\section{Metode}

Jenis penelitian yang digunakan adalah penelitian survei analitik tipe explanatory research.

Responden dalam penelitian ini sejumlah 40 responden. Pengambilan sampel dengan total sampling. Mekanisme koping untuk menurunkan cemas dan stress pada ibu dengan memberikan informasi yang jelas, memotivasi, memfasilitasi koping adaptif bagi ibu. Untuk melihat respon koping ibu dapat diketahui melalui observasi perilaku ibu.

Kriteria Eksklusi a) Primipara: fase laten kala I persalinan selama $>8$ jam dan dilatasi serviks $3-4 \mathrm{~cm}$; atau fase aktif selama $>6$ jam dan dilatasi serviks $<7 \mathrm{~cm}$ atau kala II selama $>2$ jam. B) Multipara: fase laten kala I persalinan selama $>5$ jam, dilatasi serviks $3-4 \mathrm{~cm}$; atau fase aktif selama 
Pengaruh Tingkat Kecemasan dan Mekanisme Koping Ibu Primigravida terhadap Lamanya Kala I Persalinan Spontan

$>2$ jam dan dilatasi serviks $<7 \mathrm{~cm}$ atau kala II selama $>1$ jam.

Instrumen yang digunakan lembar observasi yang isinya mengenai respon dan koping selama bersalin. Selanjutnya dilakukan wawancara selama 24 jam pertama persalinan. Diharapkan dalam 24 jam persalinan, fase-fase penting telah dilewati, sehingga ibu lebih nyaman, rileks, komunikatif dan dapat kooperatif.

Penelitian ini dilakukan di klinik bersalin swasta wilayah kerja Puskesmas Delitua Kabupaten Deli Serdang.

\section{Hasil dan Pembahasan}

Tabel 1. Distribusi Responden Berdasarkan Tingkat Kecemasan di Klinik Bersalin Swasta Wilayah Puskesmas Delitua Kabupaten Deli Serdang

\begin{tabular}{lcc}
\hline \multicolumn{1}{c}{$\begin{array}{c}\text { Tingkat } \\
\text { Kecemasan }\end{array}$} & Jumlah & Persentase (\%) \\
\hline Sedang & 19 & 47,5 \\
Berat & 20 & 50 \\
Panik & 1 & 2,5 \\
\hline Total & 40 & 100 \\
\hline \multicolumn{1}{c}{ Hasil } & pengukuran & variabel
\end{tabular}

tingkat kecemasan pada tabel 1 paling banyak responden memiliki kecemasan berat $50,0 \%$ dan paling sedikit memiliki kecemasan panik sebanyak $2,5 \%$.

Tabel 2 Distribusi Responden Berdasarkan Mekanisme Koping di Klinik Bersalin Swasta Wilayah Puskesmas Delitua Kabupaten Deli Serdang

\begin{tabular}{|c|c|c|}
\hline $\begin{array}{c}\text { Mekanisme } \\
\text { Koping }\end{array}$ & Jumlah & Persentase (\%) \\
\hline Adaptif & 26 & 65 \\
\hline Maladaptif & 14 & 35 \\
\hline Total & 40 & 100 \\
\hline
\end{tabular}

mekanisme koping pada tabel 2, lebih banyak responden dengan mekanisme koping adaptif sebanyak $65,0 \%$ dibandingkan responden dengan mekanisme koping maladaptif sebanyak $35,0 \%$.

Tabel 3. Distribusi Responden Berdasarkan Tingkat Kecemasan di Klinik Bersalin Swasta Wilayah Puskesmas Delitua Kabupaten Deli Serdang

\begin{tabular}{lcc}
\hline \multicolumn{1}{c}{$\begin{array}{c}\text { Lama Kala I } \\
\text { Persalinan }\end{array}$} & Jumlah & Persentase (\%) \\
\hline Normal & 25 & 62,5 \\
Tidak normal & 15 & 37,5 \\
\hline Total & 40 & 100 \\
\hline \multicolumn{4}{c}{ Hasil } & pengukuran & variabel
\end{tabular}

lama kala I persalinan dalam tabel 3 , lebih banyak responden dengan lama kala I persalinan normal sebanyak $62,5 \%$ dibandingkan dengan responden lama kala I persalinan tidak normal sebanyak $37,5 \%$

Tabel 4. Hubungan Tingkat Kecemasan dengan Lama Kala I di Klinik Bersalin Swasta Wilayah Puskesmas Delitua Kabupaten Deli Serdang

\begin{tabular}{|c|c|c|c|c|c|c|}
\hline \multirow{3}{*}{$\begin{array}{c}\text { Tingkat } \\
\text { Kecemasan }\end{array}$} & \multicolumn{4}{|c|}{$\begin{array}{c}\text { Lama Kala I } \\
\text { Persalinan }\end{array}$} & \multirow{2}{*}{\multicolumn{2}{|c|}{ Total }} \\
\hline & \multicolumn{2}{|c|}{ Normal } & \multicolumn{2}{|c|}{$\begin{array}{c}\text { Tidak } \\
\text { Normal }\end{array}$} & & \\
\hline & $N$ & $\%$ & $N$ & $\%$ & $N$ & $\%$ \\
\hline Sedang & 17 & 42,5 & 2 & 5 & 19 & 47,5 \\
\hline Berat & 8 & 20 & 12 & 30 & 20 & 50 \\
\hline Panik & & & 1 & 2,5 & 1 & 2,5 \\
\hline Total & 25 & 62.5 & 15 & 37,5 & 40 & 100 \\
\hline \multicolumn{3}{|c|}{ Berdasarkan } & \multicolumn{2}{|c|}{ table 4} & & atas \\
\hline terlihat & \multicolumn{2}{|c|}{ bahwa } & \multicolumn{2}{|c|}{ lebih } & \multicolumn{2}{|c|}{ banyak } \\
\hline responde & & $\mathrm{m} \epsilon$ & 111 & & & igkal \\
\hline
\end{tabular}


Pengaruh Tingkat Kecemasan dan Mekanisme Koping Ibu Primigravida terhadap Lamanya Kala I Persalinan Spontan

kecemasan berat dan panik mengalami lama kala I tidak normal sebanyak $32,5 \%$ sedangkan tingkat kecemasan sedang banyak $5 \%$.

Uji chi square menunjukkan hasil $p=0,001$ sehingga Ho tidak diterima yang artinya terdapat hubungan yang signifikan antara tingkat kecemasan dengan lama kala I persalinan.

Penelitian yang dilakukan Jetmika (1999) menemukan kaitan yang kuat antara kecemasan dengan persalinan kala I yang lama, semakin besar kecemasan maka semakin lama kala I, demikian juga sebaliknya semakin kecil kecemasan maka semakin cepat persalinan kala I.

Pada penelitian yang dilakukan ini ditemukan hasil yang bermakna antara hubungan kecemasan terhadap lama kala I persalinan spontan responden dikarenakan kecemasan yang timbul pada ibu dengan kelahiran anak pertama memberi konstribusi terhadap lamanya persalinan kala I, hal ini disebabkan ibu yang melahirkan anak pertama akan mendapatkan tekanan, merasakan cemas berlebihan, reabilitas emosi, dan adanya rasa takut jika bayi yang akan dilahirkan nanti mengalami cacat atau tidak bernafas.

Kecemasan berat pada persalinan dinilai dipengaruhi oleh rasa nyeri yang dirasakan saat persalinan kala I yaitu rasa sakit serta tidak nyaman yang dirasakan sejak awal dimulainya persalinan hingga serviks dilatasi maksimal. Hal ini dirasakan responden selama waktu berlangsungnya kala I persalinan.

Tabel 5. Hubungan Mekanisme Koping dengan Lama Kala I di Klinik Bersalin Swasta Wilayah Puskesmas Delitua Kabupaten Deli Serdang

\begin{tabular}{|c|c|c|c|c|c|c|}
\hline \multirow{3}{*}{$\begin{array}{l}\text { Mekanisme } \\
\text { Koping }\end{array}$} & \multicolumn{4}{|c|}{$\begin{array}{l}\text { Lama Kala I } \\
\text { Persalinan }\end{array}$} & \multirow{2}{*}{\multicolumn{2}{|c|}{ Total }} \\
\hline & \multicolumn{2}{|c|}{ Normal } & \multicolumn{2}{|c|}{$\begin{array}{c}\text { Tidak } \\
\text { Normal }\end{array}$} & & \\
\hline & $N$ & $\%$ & $N$ & $\%$ & $N$ & $\%$ \\
\hline Adaptif & 21 & 52,5 & 5 & 12,5 & 26 & 65 \\
\hline Maladaptif & 4 & 10 & 10 & 25 & 14 & 35 \\
\hline Total & 25 & 62.5 & 15 & 37,5 & 40 & 100 \\
\hline
\end{tabular}
responden memiliki mekanisme koping terhadap lama kala I persalinan tidak normal yaitu mekanisme kopling maladaptive $25 \%$ sedangkan yang memiliki mekanisme koping adaptif $12,5 \%$

Uji chi square memperlihatkan hasil $p=0,001$ sehingga $\mathrm{Ho}$ tidak diterima sehingga ada hubungan yang signifikan pada mekanisme koping dengan lama kala I persalinan.

Dukungan secara terusmenerus yang didapatkan ibu selama proses bersalin menyebabkan 
Pengaruh Tingkat Kecemasan dan Mekanisme Koping Ibu Primigravida terhadap Lamanya Kala I Persalinan Spontan

perasaan ibu tenang dan dapat mendorong terjadinya mekanisme koping adaptif yang membentuk impuls menuju neurotransmitter yang diteruskan ke sistem limbik lalu berlanjut ke amigdala kemudian menuju hipotalamus dan timbul rangsangan pada nukleus ventromedial dan area sekitarnya akhirnya muncul perasaan yang tenang sehingga rasa cemas berkurang dan membantu proses kelahiran menjadi normal (Guyton,2006).

\section{Dukungan yang diberikan} suami atau orang yang diinginkan ibu untuk mendampingi saat bersalin dapat membentuk meknisme koping yang positif. Proses pendampingan selama persalinan ini dapat membantu mempersingkat waktu lama persalinan karena terbentuknya koping yang positif serta ibu yang telah merasa aman, nyaman, lebih percaya diri, dan damai.

Berdasarkan analisis bivariat, variabel tingkat kecemasan dan mekanisme koping mempunyai hasil p-Value $<0,25$ maka kedua variabel masuk dalam model multivariat.

Tujuan dilakukan analisis multivariat agar didapatkan model yang terbaik. Kandidat yang ada akan diuji bersama-sama dengan menggunakan analisis regresi logistik berganda penggunaan model enter.

Pengaruh variabel independen yang meliputi tingkat kecemasan dan mekanisme koping terhadap variabel dependen disajikan dalam table 6 .

\begin{tabular}{llllll}
\multicolumn{7}{l}{ Tabel 6. Hasil Analisis Logistik Berganda } \\
\hline Variable & B & $\begin{array}{c}\text { Exp } \\
\text { (B) }\end{array}$ & SE & $\begin{array}{l}\text { P- } \\
\text { wald }\end{array}$ & $\begin{array}{l}\mathbf{9 5 \%} \\
\text { Cl }\end{array}$ \\
\hline $\begin{array}{llllll}\text { Tingkat } \\
\text { kecemasan }\end{array}$ & 2,602 & 13,48 & 0,99 & 0,00 & 1,$94 ;$ \\
& & 7 & 0 & 9 & 1 \\
\hline $\begin{array}{l}\text { Mekanisme } \\
\text { koping }\end{array}$ & 2,326 & 10,23 & 0,92 & 0,01 & 1,$67 ;$ \\
& & 3 & 4 & 2 & 0 \\
\hline Constant & - & & 0,96 & 0,00 & \\
& 3,040 & & 6 & 2 &
\end{tabular}

Berdasarkan uji wald semua variabel memiliki $p$-wald $<\mathrm{a}(0,05)$ maka variabel tingkat kecemasan dan mekanisme koping mempengaruhi lama persalinan kala I secara bermakna.

Persamaan model regresi logistik berganda yang didapat adalah: $\mathrm{P}$ (lama kala 1 persalinan $)=-$ $3.040+6,602$ (tingkat kecemasan) $+2,326$ (mekanisme koping).

Analisis yang dilakukan mendapatkan hasil variabel tingkat kecemasan memiliki dampak yang sangat besar terhadap lama persalinan kala I dinilai dari Odds Ratio $(\mathrm{OR})=13,49(95 \% \mathrm{Cl}$ 1,$94 ; 93 ; 81$ ) yang berarti ibu dengan tingkat kecemasan berat akan memiliki risiko 13 kali mengalami lama 
Pengaruh Tingkat Kecemasan dan Mekanisme Koping Ibu Primigravida terhadap Lamanya Kala I Persalinan Spontan

persalinan kala I yang tidak normal dibandingkan dengan yang tingkat kecemasan ibu sedang. Sedangkan mekanisme koping memiliki nilai Odds Ratio (OR) $=10,23 \quad(95 \% \mathrm{Cl}$ $1,67,62,60)$ yang berarti ibu dengan mekanisme koping maladaptif berisiko 10 kali mengalami lama kala I persalinan yang tidak normal dibandingkan dengan ibu dengan mekanisme koping adaptif.

Probabilitas terjadinya persalinan kala I lama tidak normal pada ibu yang tingkat kecemasan sedang jika mekanisme koping adaptif sebesar $4,6 \%$ dan jika mekanisme koping maladaptif sebesar $32,9 \%$.

Probabilitas terjadinya lama kala I persalinan tidak normal pada ibu yang memiliki tingkat kecemasan berat, jika mekanisme koping adaptif sebesar $39,2 \%$ dan jika mekanisme koping maladaptive sebesar $87 \%$.

Dibandingkan dengan mekanisme koping, pengarus kecemasan terhadap lama kala I persalinan lebih besar. Hal tersebut disebabkan karena ibu primigravida memiliki perasaan cemas yang tinggi dikarenakan pengalaman melahirkan pertama kali sedangkan mekanisme koping yang dihasilkan untuk mengatasi kecemasan kurang adaptif.
Kecemasan yang muncul dapat disebabkn karena ibu membayangkan hal-hal yang menakutkan yang mungkin terjadi selama proses persalinan, walaupun hal tersebut belum tentu terjadi (Amalia, 2009).

Menjelang proses bersalin, dalam pikiran ibu akan timbul hal-hal ynag mengkhawatirkan seperti takut bayinya akan cacat, cemas jika melahirkan dengan seksio, cemas jika persalinannya akan sulit, dan lainnya. Rasa khawatir ini akan mencapai puncak bersama dengan waktu munculnya tanda persalinan. Waktu kontraksi akan meningkat sehingga beban pikiran ibu bertambah, dan ibu semakin khawatir. Rasa khawatir pada kondisi ini jika tidak tertangani, maka dapat mengganggu konsentrasi ibu selama proses kelahiran sehingga proses yang diperkirakan lancar menjadi tidak lancar (Amalia, 2009).

\section{Simpulan}

Lama kala I persalinan normal sebanyak 25 orang (62,5\%), sedangkan responden dengan lama kala I persalinan tidak normal cukup banyak yaitu 15 orang $(37,5 \%)$.

Terdapat hubungan bermakna antara tingkat kecemasan dengan lama kala I persalinan $(p=0,001)$. 
Pengaruh Tingkat Kecemasan dan Mekanisme Koping Ibu Primigravida terhadap Lamanya Kala I Persalinan Spontan

Hasil analisis multivariat menjelaskan bahwa variabel tingkat kecemasan dan mekanisme koping secara bermakna memiliki pengaruh pada lama kala I persalinan. Tingkat kecemasan mempunyai dampak lebih besar pada lama kala I persalinan yaitu dilihat dari nilai Odds Ratio (OR) $=13,49(95 \% \mathrm{Cl} \quad 1,94 ; 93,81)$ yang berarti ibu dengan tingkat kecemasan berat beresiko 13 kali mengalami lama kala I persalinan tidak normal dibandingkan ibu dengan tingkat kecemasan sedang. Sedangkan mekanisme koping memiliki nilai Odds Ratio $(\mathrm{OR})=10,23 \quad(95 \% \mathrm{Cl}$ $1,67 ; 62,60)$ yang berarti ibu dengan mekanisme koping maladaptif berisiko 10 kali mengalami lama kala । persalinan tidak normal dibandingkan ibu dengan mekanisme koping adaptif.

Diharapkan tenaga Kesehatan selalu menjalankan standar pelayanan bagi ibu bersalin terutama dalam memberikan penjelasan dan informasi pada ibu primigravida agar ibu memiliki koping yang adaptif dan dapat menurunkan kecemasan ibu selama proses persalinan

\section{Daftar Pustaka}

Amalia, T. 2009. Kecemasan Ibu Menanti Persalinan. Dibuka pada website: http://medisdan computer.co.cc/p=384. Pada tanggal 10 september 2010.

Ambarwati. E.R. (2001). Factor- factor yang mempengaruhi kecemasan pada ibu primigravida. Dibuka pada website http://enreyambarwati.blogspot.c om/2010/04/faktor2-yang-

mempengaruhikecemasan.html. Pada tanggal 18 mei 2010.

Babak, dkk. 2005. Keperawatan Maternitas Edisi 4. Jakarta: EGC

Capernito, Lynda, Juall. (2007). Buku Saku Diagnosis Keperawatan Edisi 10. Jakarta: EGC

Chapman, Vicky, 2006. Asuhan Kebidanan Persalinan dan Kelahiran. Jakarta: EGC

Danuatmaja. B. 2004. Persalinan Normal Tanpa Rasa Sakit. Cetakan I. Jakarta: Puspa Swarna

Dinas Kesehatan Provinsi Sumatera Utara. 2008. Profil Dinas Kesehatan Provinsi Sumatera Utara.

Diponegoro, A.M, 2009. Perbedaan Kecemasan dan Lama Bersalin, Antara lbu Primipara yang Menerima dan Tidak Menerima Pendampingan Doa dan Dukungan Psikofisiologis Saat Bersalin. Yogyakarta, Vol. 6, No. 1 Januari

Guyton, Arthur. 2006. Buku Ajar Fisiologi Kedokteran. Jakarta: EGC

Hawari, D. 2011. Manajemen Stres, Cemas dan Depresi. Jakarta: FKUI

Indrawati, 2010. Faktor-faktor yang mempengaruhi Tingkat Kecemasan Pada lbu Primigravida Dalam Menghadapi Persalinan Kala I di Klinik 
Bersalin Mutiaraa Kecamatan Medan Timur Tahun 2007. Medan. Vol 11. No. 1, Maret.

Jutmika, W, 1999. Hubungan SKor Kecemasan dengan Lama Persalinan Kala I. Tesisi Semarang. Bagian/SMF Obstetri Ginekologi Fakultas Kedokteran Universitas Diponegoro.

Keliat, 2005. Proses Keperawatan Kesehatan Jiwa. Jakarta: EGC

Kosim, H. M. C. 1970. Aspek Kejiwaan dalam Kebidanann. Jakarta: NAskah Lengkap KOGEL

Lazarus, R.S Folkman S. 1984. Stress Appraisal dan Coping. New York: Springer

Lemeshow, S, et.al. 1990. Adequacy of Sample Sixa in Health Studies Diterjemahkan Oleh Dibyo Pramono dengan Judul Besar Sampel dalam Penelitian Kesehatan. 1997, Yogyakarta : Gajah Mada University Press 